\title{
Antibiotics Versus Appendicectomy for the Treatment of Uncomplicated Acute Appendicitis: An Updated Meta-Analysis of Randomised Controlled Trials by Rollins et al.
}

\author{
J. C. Harnoss ${ }^{1}$ - P. Probst ${ }^{1}$ - M. W. Büchler ${ }^{1}$ M. K. Diener ${ }^{1}$
}

Published online: 3 January 2017

(C) Société Internationale de Chirurgie 2016

\section{Dear Editors,}

We read the article by Rollins et al. [1] with great interest. This updated systematic review and meta-analysis is showing an intensive reflection of current debates and thus deserves a comment on results and its final conclusion that antibiotics should be prescribed once a diagnosis of acute appendicitis is made or considered and that the primary treatment of acute uncomplicated appendicitis should be antibiotics.

In our opinion [2], this conclusion is hastily and not supported by current available data. The main general critics are that we do not have any data about peri-interventional quality of life of our patients and no follow-up of longer than one year after initial therapy. Moreover, adverse events of the antibiotic therapy were insufficiently reported by most of trials. Besides the fact that the choice, application form, dosage and treatment duration of antibiotics are unclear, we should be aware of the risk of supporting antibiotic resistances and danger to treat malignancies with antibiotics if not performing a CT scan which will have its own drawbacks. Furthermore, none of the trials investigating antibiotics as primary therapy considered repeating hospital stays as burden of this kind of treatment.

In accordance with our results, antibiotics may prevent $62.6-72.6 \%$ of patients from appendectomies $[1,2]$. Nevertheless, going one step further, thorough and proper

M. K. Diener

markus.diener@med.uni-heidelberg.de

1 Department of General, Visceral and Transplantation Surgery and Study Center of the German Surgical Society, University of Heidelberg, Im Neuenheimer Feld 110, 69120 Heidelberg, Germany meta- and subgroup analyses revealed that treatment failure of antibiotics occurred in $46.4 \%$ up to 1 year after the initial hospital stay and the risk of complicated appendicitis was significantly increased by twofold [2]. In conclusion, surgery represents a final treatment with a clear risk profile and important factors on antibiotic therapy are yet uninvestigated (e.g. quality of life). Therefore, we plead for further RCTs and a transparent discussion of treatment options, interdisciplinary and patient-oriented in cases with suspected acute, uncomplicated appendicitis rather than a premature change of paradigm based on currently insufficient data.

Compliance with ethical standards

Conflict of interest The authors declare that they have no conflict of interest.

\section{References}

1. Rollins KE, Varadhan KK, Neal KR et al (2016) Antibiotics versus appendicectomy for the treatment of uncomplicated acute appendicitis: an updated meta-analysis of randomised controlled trials. World J Surg 40:2305-2318. doi:10.1007/s00268-016-3561-7

2. Harnoss JC, Zelienka I, Probst P et al (2016) Antibiotics versus surgical therapy for uncomplicated appendicitis: systematic review and meta-analysis of controlled trials (PROSPERO 2015: CRD42015016882). Ann Surg (epub ahead of print) 